\title{
Effect of the Thickness of Insulator Polymeric Films on the Memory Behavior: The Case of the Polymethylmethacrylate and the Polystyrene
}

\author{
J. A. Avila-Niño, ${ }^{1}$ A. O. Sustaita, ${ }^{2}$ M. Reyes-Reyes, ${ }^{1}$ and R. López-Sandoval ${ }^{2}$ \\ ${ }^{1}$ Instituto de Investigación en Comunicación Optica, Universidad Autónoma de San Luis Potosí, Alvaro Obregon 64, \\ 78000 San Luis Potosí, SLP, Mexico \\ ${ }^{2}$ División de Materiales Avanzados, IPICYT, Camino a la Presa San José 2055, Colonia Lomas 4a Sección, \\ 78216 San Luis Potosí, SLP, Mexico
}

Correspondence should be addressed to R. López-Sandoval, sandov@ipicyt.edu.mx

Received 2 February 2011; Revised 7 July 2011; Accepted 20 July 2011

Academic Editor: Werner Blau

Copyright ( $\odot 2011 \mathrm{~J}$. A. Avila-Niño et al. This is an open access article distributed under the Creative Commons Attribution License, which permits unrestricted use, distribution, and reproduction in any medium, provided the original work is properly cited.

The effect of thickness variation on the memory behavior of the polymethylmethacrylate-(PMMA)-based devices has been investigated. The PMMA film thicknesses have been varied between 5 to $300 \mathrm{~nm}$, and we have found that the film thickness determines the type of behavior: ohmic, write-once-read-many-times (WORM) memory with two ON states, WORM memory with a negative differential resistance (NDR) region, and WORM memory without NDR region. The fact that similar results were obtained using different solvents to dilute PMMA (chlorobenzene, chloroform, and dimethyl sulfoxide), as well as using an other insulating polymer such as polystyrene (PS), leads to the conclusion that the phenomenon of memory depends on the aluminum electrodes, organic film thickness, and the compliance current used during the electroformation whereas the type of organic layer (PMMA or PS) has minor influence. From here, we conclude that the conductivity switching of the insulator organic film is due to the injection of aluminum particles into the film during the first voltage cycle.

\section{Introduction}

Since the last decade, there has been an intensive research in the field of organic electronics, the organic memory devices being one of the emerging research areas in this field. A considerable number of architectures as well as materials for the development of devices with memory effect has been proposed [1-3]. Among the principal thin-film structures that have been reported are metal-organic insulator-metal (MIM) [4-14], metal-organic-metal-organic-metal [1517], metal nanoparticles embedded in the organic layer in MIM architecture [18], devices where the embedded metal nanoparticles are replaced with organic particles such as fullerenes [19-21], and carbon nanoshells [22]. From all, the simplest architecture and one of the first to show memory behavior was the MIM architecture. One of the pioneer works was realized by Simmons and Verderber [23], who used a thin film of $\mathrm{SiO}_{2}$ inorganic insulator with a thickness in the order of nanometers between two metallic electrodes. The authors explained this phenomenon as the creation of charge traps in the inorganic film due to an electric field. However, different theories have been proposed in order to explain such phenomena, one of them by Thurstans and Oxley [24] who proposed the effect of electroformation. They mentioned that once a voltage was applied on the device, an electric field was induced and this field moves the metal particles coming from the electrodes into the organic film, where they form metallic islands. These islands are responsible of the charge conduction by tunneling through filamentary pathways. The same kind of memory behaviors, mentioned before, has been reported using organic insulators. For example, Tondelier et al. [4] have obtained basically the same effect reported by Simmons and Verderber [23] in $\mathrm{Al} /$ pentacene / $\mathrm{Al}$ devices, that is, the threshold voltage varies 
almost linearly with the thickness of the organic film and, above certain critical thickness, the organic layer behaves like an insulator. On the other hand for thinner films, the device has an ohmic behavior. They argued that this phenomenon is due to the possible inclusion of aluminum nanoparticles in the pentacene film during the evaporation of the top electrode. On the other hand, Cölle et al. [5] explain the memory effect in organic devices arguing the existence of multiple filament pathways, which appear and disappear at the same place in the organic film at the moment of write and erase of the device, respectively. These filaments were associated with spots observed by infrared microscopy images. They have used polymers with different chemical structures and bandgaps, such as polystyrene (PS) and polyspirofluorene as organic insulator layers, and the thickness of spin-coated polymer films were varied between $60 \mathrm{~nm}$ and $170 \mathrm{~nm}$. Their results suggest that an oxide film, inherent to the aluminum bottom electrode, is responsible for this phenomenon. In a last paper [6], this group included deliberately an $\mathrm{Al}_{2} \mathrm{O}_{3}$ film in polyspirofluorene MIM devices and, from here, they have concluded that the memory effect is related to a native aluminum oxide layer. This layer is responsible for the resistive switching effect and the organic film only acts as a series resistance. However, other authors have found bistable electrical switching in PS and other insulator polymer thin films $(50-400 \mathrm{~nm})$ fabricated by a glow discharge deposition technique, although they have used gold electrodes [25-27]. Even more, Joo et al. found that spin-coated PS and polymethyl methacrylate (PMMA) films sandwiched between a bottom aluminum electrode $(80 \mathrm{~nm})$ and top copper electrode $(80 \mathrm{~nm})$ did not show memory behavior [28]. Therefore, the memory behavior of insulator organic films depends on many experimental parameters, which must be studied.

In this work we use PMMA and PS as organic insulator layers of MIM devices. We have studied the effect of the film thickness on the memory behavior, varying their thicknesses from $7.5 \mathrm{~nm}$ up to $300 \mathrm{~nm}$. We have found that the thin PMMA films as well as thin PS films show a WORM memory behavior beyond a critical thickness. In general, the state ON of these devices is obtained at $2 \mathrm{~V}$. In addition, three different kinds of solvents were used in the spin-coating process and these solvents do not change the electrical behavior of the devices. This indicates that the effect is only associated to the film thickness. Furthermore, our results show that aluminum electrodes in $\mathrm{Al} /$ organic insulator/Al devices are responsible for WORM memory and that the type of organic insulator layer (PMMA and PS) only has a minor influence. Therefore, our results suggest that conductive filaments are formed under electrical stress that causes migration of electrode material into the polymeric film.

\section{Experimental}

Our device architecture is a sandwich type metal/organic insulator/metal deposited over a glass substrate (Figure 1). The substrates of Dow corning glass were ultrasonically cleaned, successively, in acetone, methanol, and isopropyl alcohol for

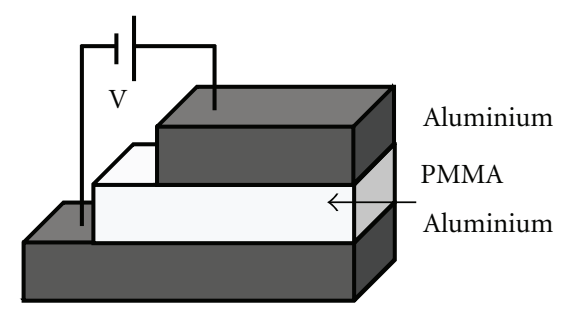

FIgURE 1: Schematic diagram of the memory device.

20 minutes at each step, dried in an oven at $50^{\circ} \mathrm{C}$, and, finally, they were exposed in a UV-ozone ambient for 45 minutes. The bottom electrode was deposited by thermal evaporation at a pressure of $1 \times 10^{-6}$ Torr. The metal used in these devices was aluminum, and, as organic films, we have used PMMA (Aldrich, $\mathrm{Mw}=15,000$ ) as well as PS (Aldrich, $\mathrm{Mw}=97,400$ ). After the deposition of the bottom aluminum electrode, the polymer solution was deposited by the spin-coating method at $4500 \mathrm{rpm}$ for 40 seconds. The PMMA and PS were diluted in different solvents such as chloroform (CF), chlorobenzene (CB), and dimethyl sulfoxide (DMSO). The solutions prepared at different concentrations of PMMA (Table 1) were magnetically stirred by around 12 hours and then spin coated on the bottom electrode. The films were annealed at $80^{\circ} \mathrm{C}$ for 90 minutes in a controlled atmosphere of nitrogen. After that, the top aluminum electrode was evaporated using the same process described before for the bottom electrode. The thickness of both aluminum electrodes was around $50 \mathrm{~nm}$ and the active area of the cells was $6 \mathrm{~mm}^{2}$. The thicknesses of the thermally evaporated metal electrodes and organic film were measured using an Alpha Step 500 surface profiler (from Tencor Instruments, Inc.). Electrical characterization of the devices was performed in ambient condition without any device encapsulation. The $I-V$ measurements were performed by using a Keithley 236 source measure unit. The compliance current was set, in general, at $100 \mathrm{~mA}$. The contacts between the Al electrodes and the Keithley source unit were made with gold spring probes. In general, the sweeps of the voltages were continuously applied and the speed of these measurements was $2 \mathrm{~V} / \mathrm{s}$. The electrical properties of the MIM devices were similar, no matter the polarity between the top and bottom electrodes during the voltage sweeps. The top electrode and the polymer films of the devices were examined by using scanning electron microscopy (SEM) and atomic force microscopy (AFM). SEM images were taken using an FEI FEG-XL30 operating at $8 \mathrm{kV}$.

\section{Results and Discussion}

First, we examined the memory behavior as a function of the PMMA film thickness obtained from the spin coating of PMMA/CB, PMMA/CF, and PMMA/DMSO solutions. The PMMA films are embedded between two aluminum electrodes. Figure 2 shows typical $I-V$ curves of PMMA (using CB) thin-film devices, which are presented on semilogarithmic scale. The curves were measured applying a bias voltage between both electrodes and with a compliance current set 
TABLe 1: Al/PMMA/Al devices fabricated by using different solvents.

\begin{tabular}{|c|c|c|c|c|}
\hline Concentration & Solvent & Thickness & Response & $\begin{array}{c}\text { Current }(\mathrm{mA}) \\
\text { read at } 1 \mathrm{~V}\end{array}$ \\
\hline $2.5 \mathrm{mg} / \mathrm{mL}$ & $\mathrm{CB}$ & $7.5 \mathrm{~nm}$ & Ohmic & $5 \times 10^{-2}$ \\
\hline $5 \mathrm{mg} / \mathrm{mL}$ & CB & $17 \mathrm{~nm}$ & $\begin{array}{l}\text { WORM with } \\
\text { two ON states }\end{array}$ & $\begin{array}{c}5 \times 10^{-2} \mathrm{ON}_{1} \\
10^{-3} \mathrm{ON}_{2}\end{array}$ \\
\hline $10 \mathrm{mg} / \mathrm{mL}$ & CB & $22 \mathrm{~nm}$ & $\begin{array}{l}\text { WORM with } \\
\text { NDR }\end{array}$ & $10^{-3}$ \\
\hline $40 \mathrm{mg} / \mathrm{mL}$ & $\mathrm{CB}$ & $90 \mathrm{~nm}$ & WORM & $10^{-4}$ \\
\hline $60 \mathrm{mg} / \mathrm{mL}$ & $\mathrm{CB}$ & $140 \mathrm{~nm}$ & WORM & $10^{-6}$ \\
\hline $120 \mathrm{mg} / \mathrm{mL}$ & $\mathrm{CB}$ & $250 \mathrm{~nm}$ & Insulator & $10^{-9}$ \\
\hline $0.7 \mathrm{mg} / \mathrm{mL}$ & $\mathrm{CF}$ & $5 \mathrm{~nm}$ & Ohmic & $5 \times 10^{-2}$ \\
\hline $1.5 \mathrm{mg} / \mathrm{mL}$ & CF & $11 \mathrm{~nm}$ & $\begin{array}{l}\text { WORM with } \\
\text { two ON states }\end{array}$ & $\begin{array}{c}5 \times 10^{-2} \mathrm{ON}_{1} \\
10^{-3} \mathrm{ON}_{2}\end{array}$ \\
\hline $2.5 \mathrm{mg} / \mathrm{mL}$ & $\mathrm{CF}$ & $22 \mathrm{~nm}$ & $\begin{array}{l}\text { WORM with } \\
\text { NDR }\end{array}$ & $10^{-3}$ \\
\hline $5 \mathrm{mg} / \mathrm{mL}$ & CF & $37 \mathrm{~nm}$ & WORM & $10^{-4}$ \\
\hline $20 \mathrm{mg} / \mathrm{mL}$ & CF & $160 \mathrm{~nm}$ & WORM & $10^{-7}$ \\
\hline $30 \mathrm{mg} / \mathrm{mL}$ & $\mathrm{CF}$ & $300 \mathrm{~nm}$ & Insulator & $10^{-9}$ \\
\hline $4 \mathrm{mg} / \mathrm{mL}$ & DMSO & $5 \mathrm{~nm}$ & Ohmic & $5 \times 10^{-2}$ \\
\hline $9 \mathrm{mg} / \mathrm{mL}$ & DMSO & $15 \mathrm{~nm}$ & $\begin{array}{l}\text { WORM with } \\
\text { two ON states }\end{array}$ & $\begin{array}{c}5 \times 10^{-2} \mathrm{ON}_{1} \\
10^{-3} \mathrm{ON}_{2}\end{array}$ \\
\hline $17.5 \mathrm{mg} / \mathrm{mL}$ & DMSO & $25 \mathrm{~nm}$ & $\begin{array}{l}\text { WORM with } \\
\text { NDR }\end{array}$ & $10^{-3}$ \\
\hline $40 \mathrm{mg} / \mathrm{mL}$ & DMSO & $40 \mathrm{~nm}$ & WORM & $10^{-4}$ \\
\hline
\end{tabular}

at $100 \mathrm{~mA}$, which is the default compliance current of the Keithley 236 source measure unit. The first voltage sweep was performed from 0 to $8 \mathrm{~V}$, then from 8 to $-8 \mathrm{~V}$, and finally from -8 to $8 \mathrm{~V}$. The $I-V$ curves show different responses as a function of the thickness of the organic film (Figures 2(a)$2(\mathrm{~d})$ ). For a thickness around $7.5 \mathrm{~nm}$, the device shows an ohmic behavior with no threshold voltage and the current is the order of $100 \mathrm{~mA}$ (Figure 2(a)). This behavior can be readily understood and it is related with electron tunneling processes [29]. In addition, it is also possible that some metallic particles are introduced into the polymer during the evaporation process of the top electrode forming metallic filaments.

As the film thickness continues increasing, the $I$ $V$ curves begin to show memory effect with different behaviors, such as is observed in Figures $2(\mathrm{~b})-2(\mathrm{~d})$. The devices with thicknesses around $17 \mathrm{~nm}$ (Figure 2(b)) exhibit an abrupt transition occurring at a threshold voltage $\left(V_{\text {th }}\right)$ of $2 \mathrm{~V}$, where the $I-V$ curve changes from a high-impedance $(\mathrm{OFF})$ state to low-impedance $(\mathrm{ON})$ state. In higher voltage region $\left(|V|>V_{\text {th }}\right)$, during the positive and negative voltage sweeps, the electrical current was saturated. When the voltage was scanned from 8 to $-8 \mathrm{~V}$, the memory device switched to other $\mathrm{ON}$ state around $-6 \mathrm{~V}$. This implies that devices with this thickness and in this voltage interval show multilevel conductance states $[5,10]$. After that the device switched to the second ON state, the conductivity remains basically at the same state during the following sweep cycles indicating that we have a write-once-read-many times (WORM) memory.
A third type of behavior occurs for a PMMA film with a thickness around $22 \mathrm{~nm}$ (Figure 2(c)). The device initially exhibited a low-conductivity state (the OFF state) and, as the applied voltage was increased, a threshold voltage at $2 \mathrm{~V}$ was observed. The device switched to ON state and exhibited a region of negative differential resistance (NDR), which only occurs in the first positive sweep $(0 \rightarrow 8 \mathrm{~V})$. During the opposite voltage sweep $(8 \mathrm{~V} \rightarrow 0 \mathrm{~V} \rightarrow-8 \mathrm{~V})$, the device remains in the $\mathrm{ON}$ state and it does not show a threshold voltage. A second sweep shows that once the device has reached its ON state, this remains there (Figure 2(c)). In fact, this state was also observed over 1000 read voltages and even when the power is turned off. Once again, we have obtained a WORM memory. When the film thickness is bigger than those previously described, the memory devices present the same WORM behavior (Figure 2(d)). However, the electrical current of the $\mathrm{ON}$ state decreases respect to the thinner organic films (Figures 2(b) and 2(c)), such as is shown in Table 1. In addition, Figure 2(d) shows that the device, for thick films $(140 \mathrm{~nm})$, has very low conductivity. Finally, when the polymer film is thick enough (around $300 \mathrm{~nm}$ ), the device has an insulator behavior. In general, all the WORM memory devices reported in this work, no matter the thickness, show good retention for thousands of cycles and even days, without any encapsulation such as is shown in Figure 3 for an Al/PMMA/Al device with a thickness of $22 \mathrm{~nm}$.

To study the effect of different solvents on the electrical response of PMMA thin films, memory devices were fabricated using CF and DMSO. It was observed that $I-V$ measurements are independent of the used solvent (CB, CF, and DMSO) and only depend of the thickness of the films. This means that the same memory behavior was observed at a specific range of thickness, no matter the solvent employed. However, as is shown in Table 1, the thickness depends on the used solvent as well as of the PMMA concentration. In general, we obtain that PMMA films (i) with thicknesses smaller than $10 \mathrm{~nm}$ show ohmic behavior, (ii) with thicknesses between 11-20 nm show WORM memory with two ON states, (iii) with thicknesses between $20-25 \mathrm{~nm}$ show WORM memory with NDR, (iv) with thicknesses bigger than $25 \mathrm{~nm}$ only show WORM memory, and, finally, (v) with thicknesses bigger than $300 \mathrm{~nm}$ show an insulator behavior. For the PS memory devices fabricated by using different solvents, the results were similar to those obtained with PMMA, such as is shown in Figure 4. We found only small differences in the thickness ranges for the different memory behaviors. For example, the WORM memory with multilevel ON states, it is now observed from $8 \mathrm{~nm}$ up to $14 \mathrm{~nm}$ and the WORM memory with NDR starting from $15 \mathrm{~nm}$. In order to determine the exact thickness range, it is necessary to do more experiments. However, the results already show that small changes to some experimental parameters can lead to significant changes in the electrical behavior.

To understand the effect of the different thicknesses on the electrical properties of PMMA films, we have studied their morphology. Figure 5 shows the morphology of two PMMA films with two different thicknesses, $9 \mathrm{~nm}$ and $15 \mathrm{~nm}$ (Figures 5(a) and 5(b), resp.), which were fabricated using 


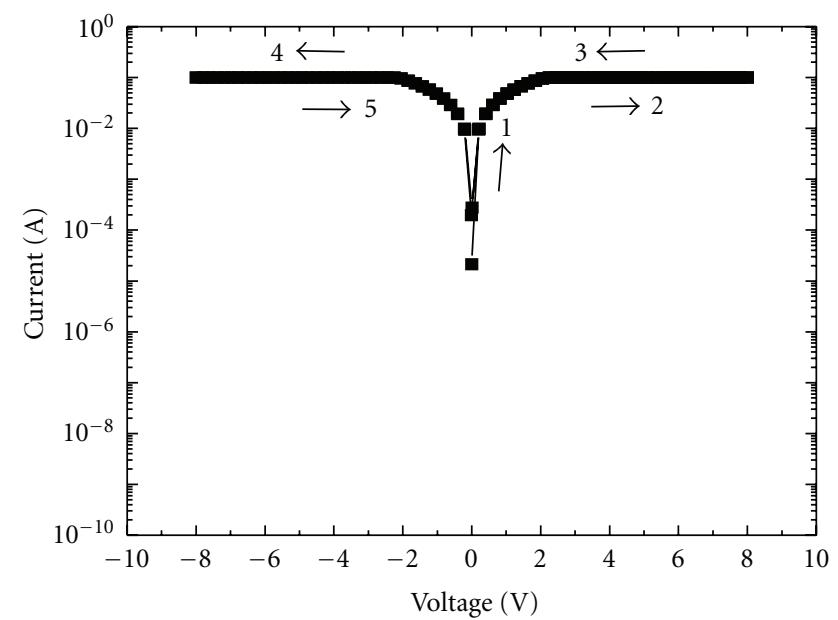

(a)

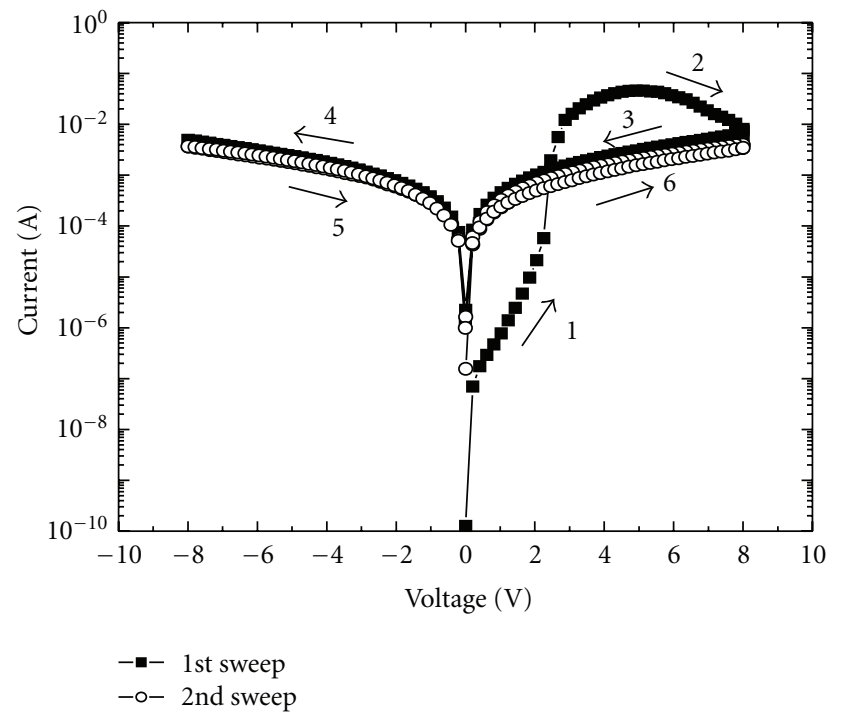

(c)

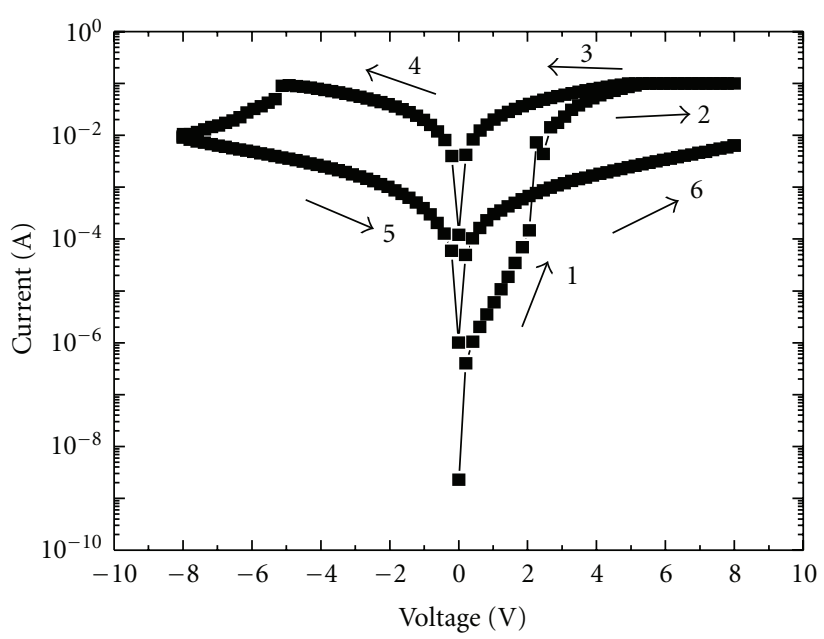

(b)

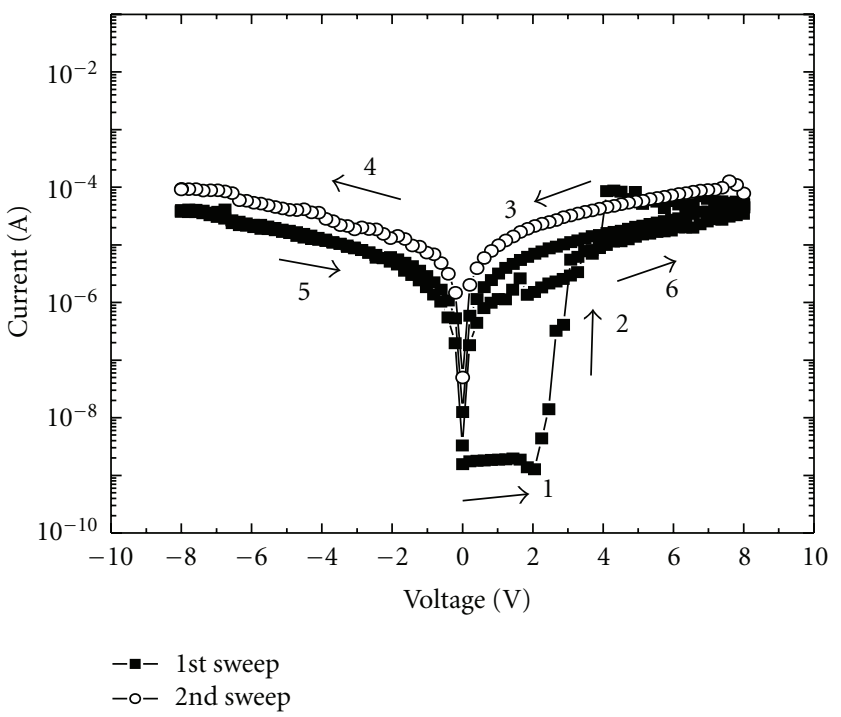

(d)

Figure 2: $I-V$ response of the Al/PMMA/Al devices as a function of PMMA thickness: (a) $7.5 \mathrm{~nm}$, (b) $17 \mathrm{~nm}$, (c) $22 \mathrm{~nm}$, and (d) $140 \mathrm{~nm}$. The devices were fabricated using CB as solvent. It can be appreciated that the $I-V$ response changes as a function of the PMMA thickness.

CB. They were studied by AFM and the film with $15 \mathrm{~nm}$ reveals a good deposition with a small roughness about $0.3 \mathrm{~nm}$. In general, all the films processed with the different solvents show good deposition, except the films smaller than $10 \mathrm{~nm}$. The latter present an ohmic behavior (Figure 5(a)) and they show holes inside the film of the same order of the film thickness. These holes are responsible for the ohmic behavior because they cause a short circuit between the electrodes. Similar AFM images were reported by Pyo and coworkers for AIDNC films in the same thickness range [30]. On the other hand, the films with thicknesses bigger than $10 \mathrm{~nm}$ do not show holes, therefore, they are not responsible of their WORM memory behavior. The changes in the electrical properties of the devices could be related with the introduction of metal particles into the polymeric films. These metal particles could come from the top electrode, when this is thermally evaporated, as well as from both electrodes when the voltage is increased during the first voltage sweep. In this way, this injection of metal particles could produce metallic filaments inside the polymeric films, which would be responsible for the polymer conductivity increase. The switching from the first state $\mathrm{ON}$ to the second one in Figure 2(b) and the NDR in Figure 2(c) would correspond to the destruction of weakest metallic filaments due to the Joule heating, when a higher voltage is applied, which are not reformed during the subsequent voltage cycles. To elucidate if the filamentary formation is the responsible mechanism for the WORM memory behavior, we have examined the effect of the voltage on the films by SEM.

Reproducible bistable switching has been reported in devices based on PS thin films and other insulator polymers $[5,24-26]$. To know if the WORM memory behavior of our devices is a consequence of the interval of used voltages, the interval was increased to study how this affects their electrical 


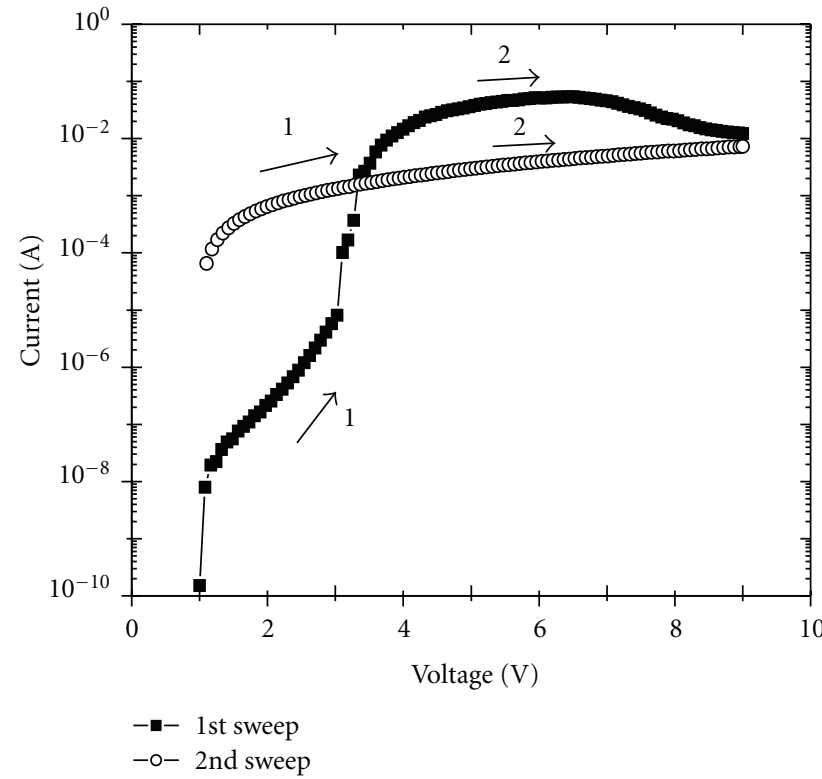

(a)

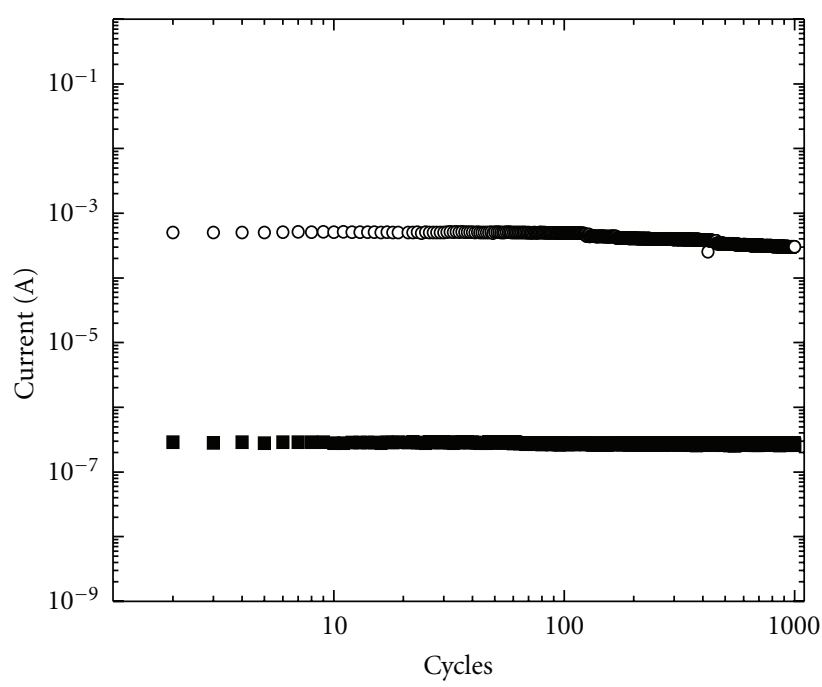

- OFF state

- ON state

Figure 3: (a) $I-V$ curve of an Al/PMMA (22 nm)/Al device. PMMA was dissolved with CB. (b) Effect of the read cycles on the stability of the On and Off states. The read voltage was set at $1 \mathrm{~V}$.

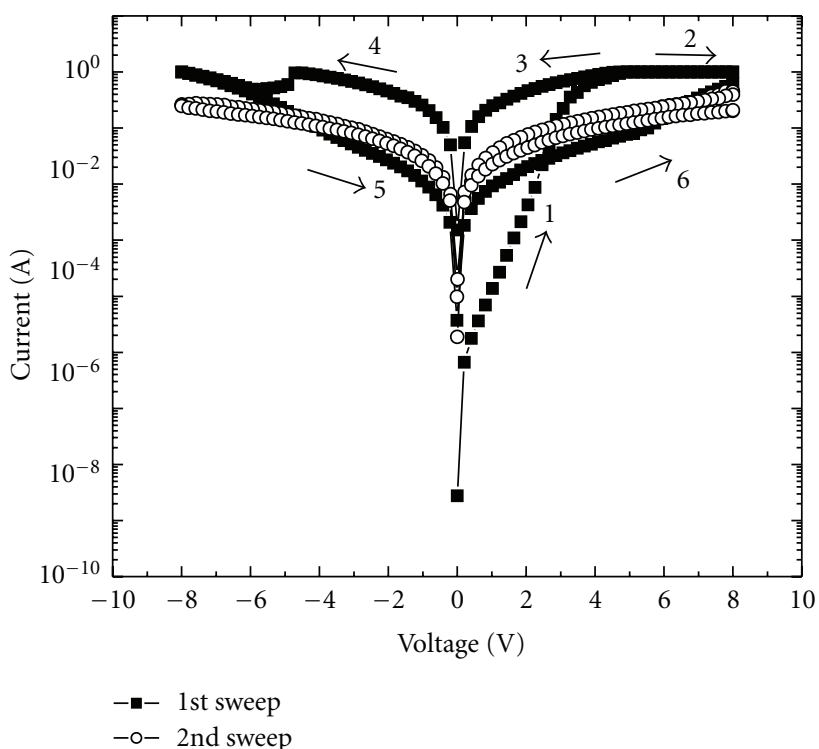

(a)

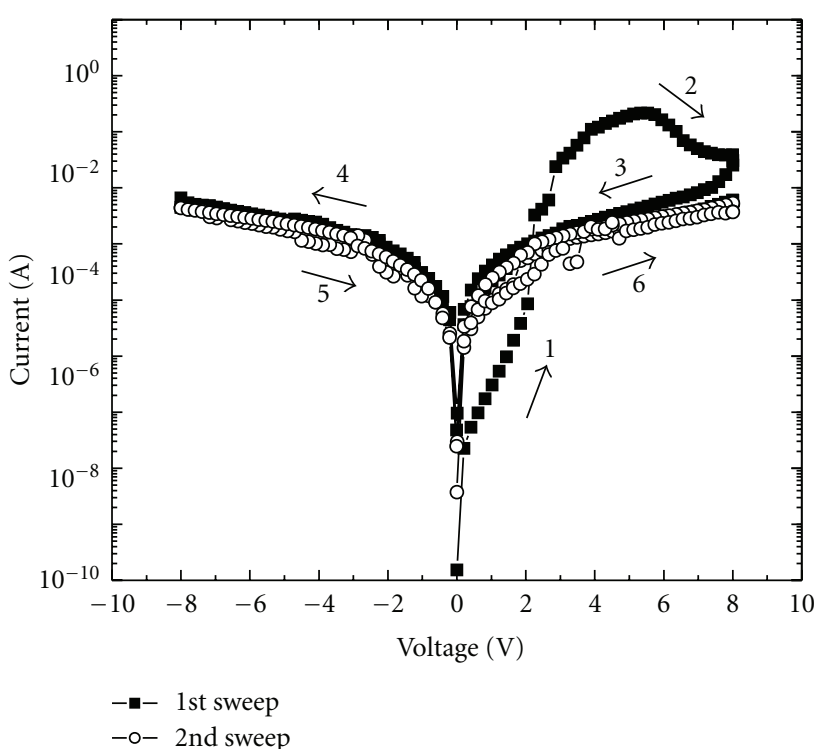

(b)

Figure 4: $I$ - $V$ response of Al/PS/Al devices. PS was dissolved with CB, for two different PS thicknesses: (a) $11 \mathrm{~nm}$ and (b) $18 \mathrm{~nm}$. Note that the results are basically similar to those of PMMA devices in a similar thickness range.

and morphological properties. Figure 6 shows the $I-V$ curves of Al/PMMA/Al devices with an organic thickness film of $22 \mathrm{~nm}$. As it was mentioned earlier, the devices with this thickness showed a WORM memory behavior with NDR for voltage sweeps from 0 to 8,8 to -8 , and -8 to $8 \mathrm{~V}$. To study the morphological changes and damages caused by the application of voltage sweeps to the PMMA film [31], it is necessary to remove the top aluminum electrode. However, removing the top electrode without damaging the polymer layer would be very complicated. Therefore for achieving this goal, a $10 \mathrm{~nm}$ polyvinyl alcohol (PVA) layer was spin coated between the top electrode and the $22 \mathrm{~nm}$ PMMA layer, which was removed with water after the voltage cycle application. Note that we are changing the total thickness of the device and, as a consequence, the $I-V$ characteristics, but our goal here was to study in a qualitative way the effect 


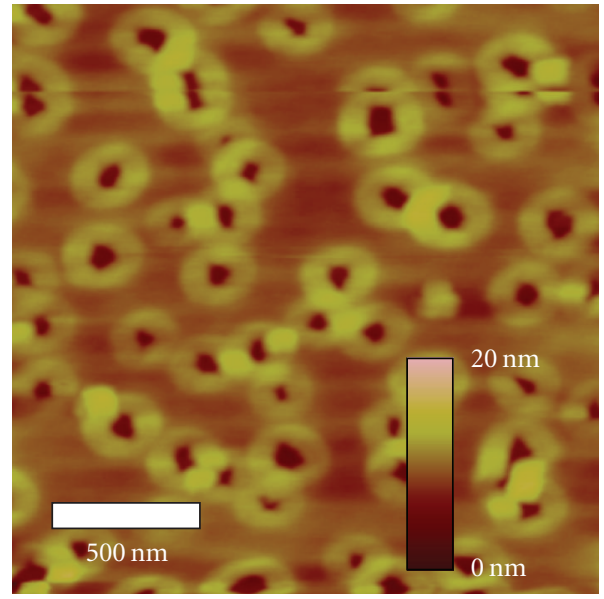

(a)

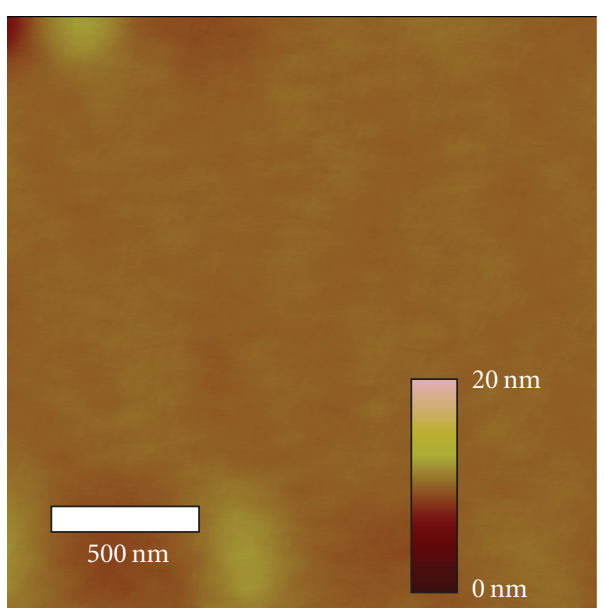

(b)

Figure 5: AFM images of the PMMA films over glass substrates with a thickness of (a) $9 \mathrm{~nm}$, which corresponds to $I$ - $V$ ohmic response and (b) $15 \mathrm{~nm}$, which corresponds to $I-V$ response with two ON states.

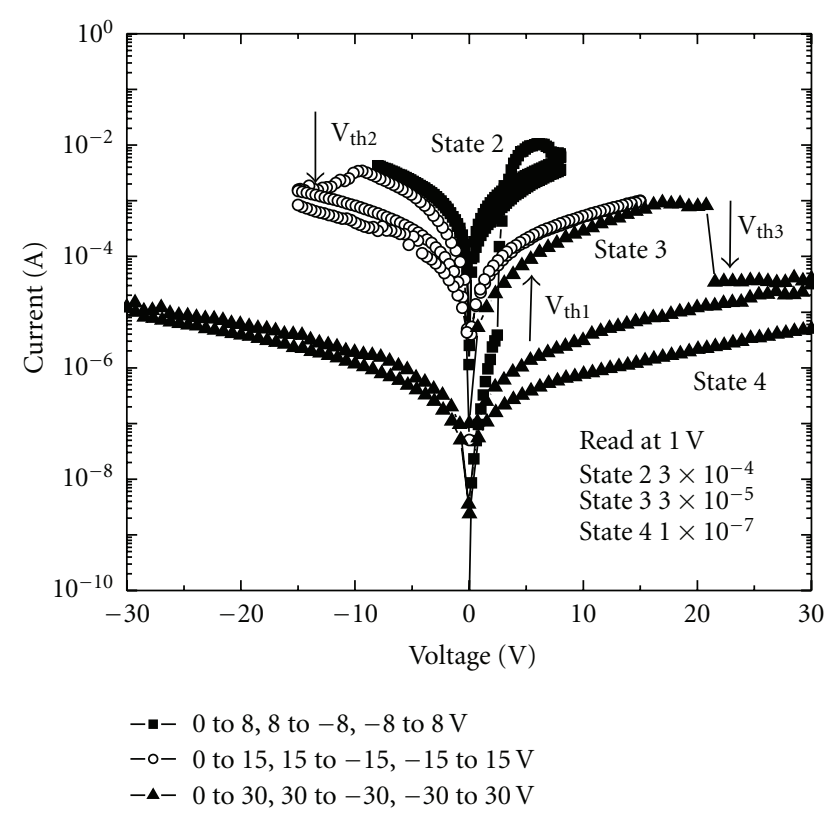

Figure 6: $I-V$ response of an Al/PMMA (22 nm)/Al memory device. In addition to the threshold voltage at $2 \mathrm{~V}$, threshold voltages at -12 and $20 \mathrm{~V}$ are observed.

of the electric field on the top electrode and PMMA film of the memory device. Furthermore, the total thickness (32 nm) of the PVA-PMMA layer is similar to films with WORM behavior (see Figure 2(d) and Table 1). The top electrode and the PMMA layer were observed by using SEM. From the Figures 7(a) and 7(b) no appreciable damages on PMMA layer and on the bottom surface of the top electrode were observed when cycles of $8 \mathrm{~V}$ were applied, compared with the pristine ones. From elemental mapping SEM photographs, we were unable to observe properly the aluminum particles in the films because the signal coming from the bottom aluminum electrode interfered. However, this inconvenience was resolved using ITO as the bottom electrode, instead of Al. From the elemental mapping, we observe the injection of aluminum particles into the film, in this way filamentary formation is occurring.

When the interval of used voltages was extended, the MIM device with $22 \mathrm{~nm}$ of thickness showed other threshold voltages at -15 and $20 \mathrm{~V}$ (Figure 6), which indicate the formation of several levels of electrical conduction. These new levels of electrical conductance were obtained by using the following procedure. A voltage sweep from 0 to $-15 \mathrm{~V}$ was applied and, at around $-12 \mathrm{~V}\left(V_{\mathrm{th} 2}\right)$, the device conductivity switched from state 2 to state $3\left(3 \times 10^{-5} \mathrm{~A}\right.$ read at $\left.1 \mathrm{~V}\right)$. During this voltage sweep, we note that the top electrode begins to burn, possibly due to the Joule heating. We consider that this damage on the top electrode is the responsible mechanism of the decrease in the conductivity $[25,26,32]$. In the subsequent voltage scans (from -15 to $15 \mathrm{~V}$ and from 15 to $-15 \mathrm{~V}$ ) the device remains in the state 3 , even when the supply is turned off. Finally, a voltage scan was performed from 0 to $30 \mathrm{~V}$. In this sweep, the device shows another conductivity switching at around $20 \mathrm{~V}\left(V_{\text {th } 3}\right)$ from state 3 to state $4\left(1 \times 10^{-7} \mathrm{~A}\right.$ read at $\left.1 \mathrm{~V}\right)$. The conductivity remains there for the following voltage sweep (from 30 to $-30 \mathrm{~V}$ and from -30 to $30 \mathrm{~V}$ ). To quantify the damages of the higher voltage cycle on the top electrode and PMMA layer, we have realized the same procedure described before in order to study, by using SEM, the physical damages on the devices as a consequence of the voltage application. For this, cycles from 0 to $20 \mathrm{~V}$, from 20 to $-20 \mathrm{~V}$, and from -20 to $20 \mathrm{~V}$ were applied to a device fabricated with a PVA layer of $10 \mathrm{~nm}$ and PMMA layer of $22 \mathrm{~nm}$. We observe that at voltage around $20 \mathrm{~V}$, the PVAPMMA device begins to burn similarly to the films without PVA. Figures $7(\mathrm{c})$ and $7(\mathrm{~d})$ show the effects of the strong electric fields in the polymer and aluminum layers, respectively. From Figure 7(c), the formation of circular craters in the polymer layer can be appreciated, where material appears 


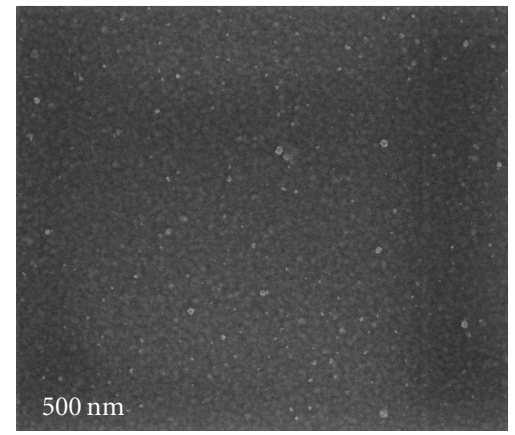

(a)

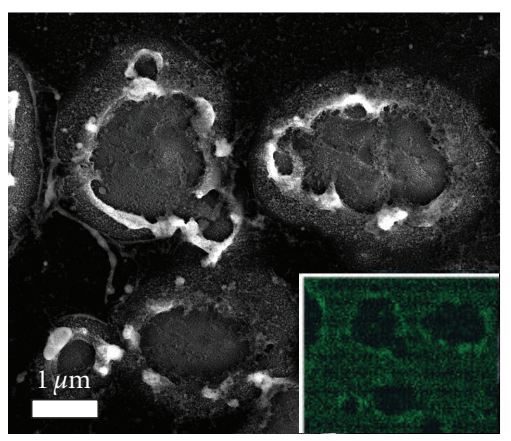

(c)

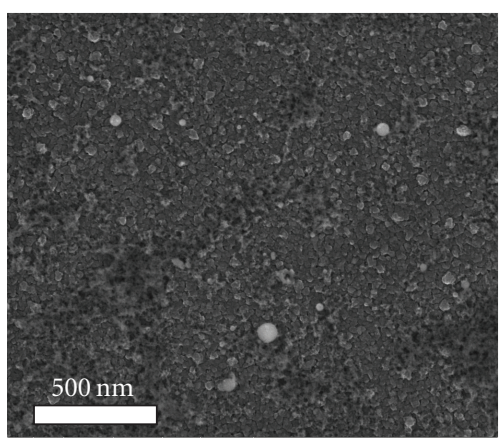

(b)

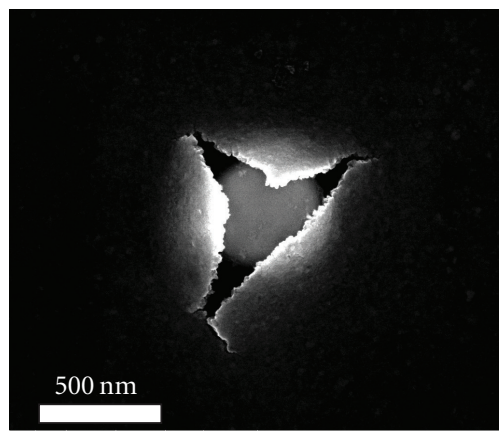

(d)

Figure 7: SEM images of (a) polymer layer and (b) the top aluminum electrode show no damage when cycles of $8 \mathrm{~V}$ were applied to the $\mathrm{Al} / \mathrm{PVA}(10 \mathrm{~nm})$-PMMA (22 nm)/Al device. Contrary to the first case, when cycles of $20 \mathrm{~V}$ were applied, SEM images show physical damages in both, (c) the PMMA layer and the (d) top aluminum electrode. The inset of (c) shows the aluminum elemental mapping of the PMMA layer.

to be ejected, and, from the inset of the figure, the removal of the aluminum particles from the craters. On the other hand, Figure 7 (d) shows the rupture on the bottom surface of the top aluminum layer. Therefore, these damages in the top electrode and in the PMMA film come from Joule heating as well as the intense electric fields, and they are responsible for the conductivity decrease. Thus, the existence of these $\mathrm{ON}$ multistates for high-voltage application is consequence of damages to the device and suggests that once the metallic filaments have been broken, it is impossible for them to be reformed. other possible explanation could be that the rate of rupture or destruction of filaments is bigger than their formation.

Other important variable in the filamentary formation is the compliance current. In Figure 8, we compare the effect of the compliance current on the electrical properties of a $17 \mathrm{~nm}$ PMMA memory. First, we have electroformed the device using a compliance current of $20 \mathrm{~mA}$ and the voltage bias was swept from 0 to $8 \mathrm{~V}$. After that, we have studied as the formation and rupture of filaments depend on the compliance current and the voltage interval. Note that all experiments were performed on the same device. When the compliance current is low, $40 \mathrm{~mA}$, we observe (Figure 8(a)) that the $I-V$ curves almost remain the same. This may occur because at low-compliance currents, possibly, there is no rupture or formation of new filaments. Another possible explanation is that the rate of formation of new filaments is equal to the rate of their rupture. The increase of the compliance current to $60 \mathrm{~mA}$ (Figure 8(b)) shows similar results to those reported for $40 \mathrm{~mA}$, although in the first sweep of the voltage, we observe the formation of new filaments and, possibly, the rupture of the weakest. When the compliance current was increased to $80 \mathrm{~mA}$ (Figure 7(c)), we observe formation of new filaments, in the first sweep of voltage, but since the second sweep, the destruction of filaments due to Joule heating is much larger than their formation. Thus, the conductivity of the MIM device decreases sharply. We performed five sweeps of voltage on the device, and we did not observe the recovery of the initial conductivity. This indicates that at high-compliance currents, once the filaments are broken due to Joule heating, these are difficult to reform or the rate of formation of filaments is much less than their rupture. In addition, we have studied the possibility of increasing the rate of formation of filaments with respect to their rupture. For this, the bias voltage was swept from 0 to $12 \mathrm{~V}$, and the compliance current was decreased from $80 \mathrm{~mA}$ to $60 \mathrm{~mA}$. Figure 7(d) shows that the conductivity increases in the first and second voltage sweeps, indicating that the rate of filament formation is higher than its rupture or destruction. This conductivity recovery can be related with a new influx of metallic particles coming from fractures of the electrodes due to the electric field and, as consequence, the formation of new filaments. In the third sweep of the voltage, the rate of broken filaments is higher 


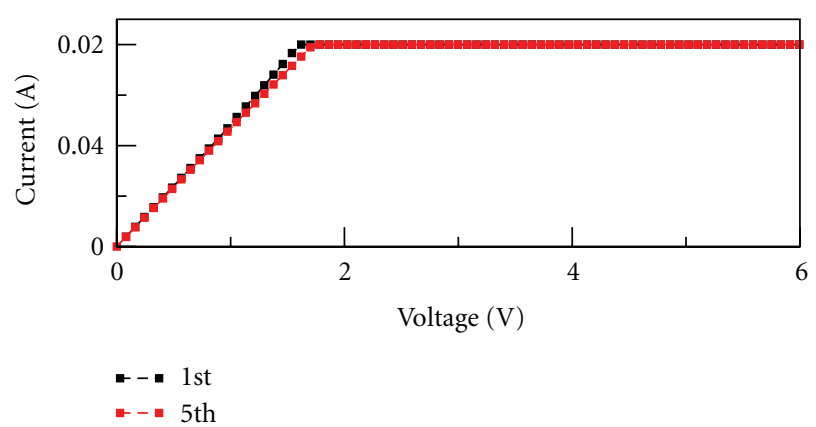

(a)

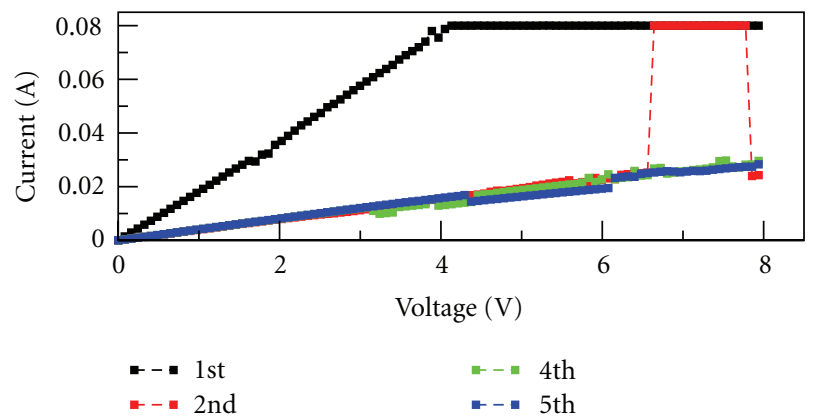

(c)

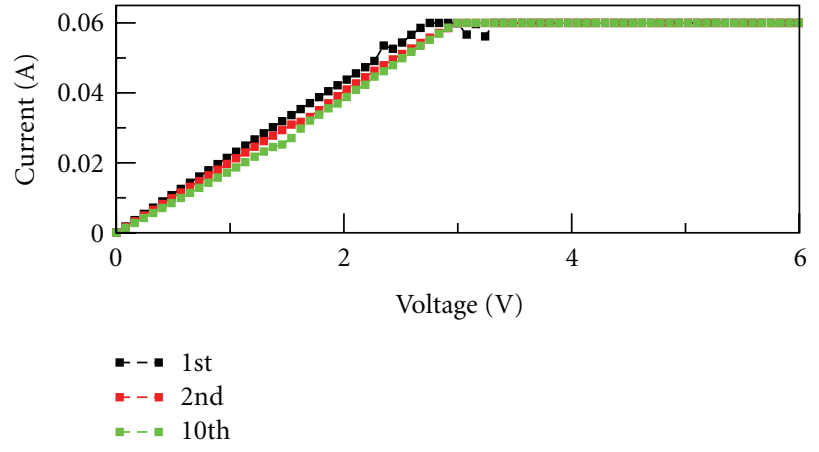

(b)

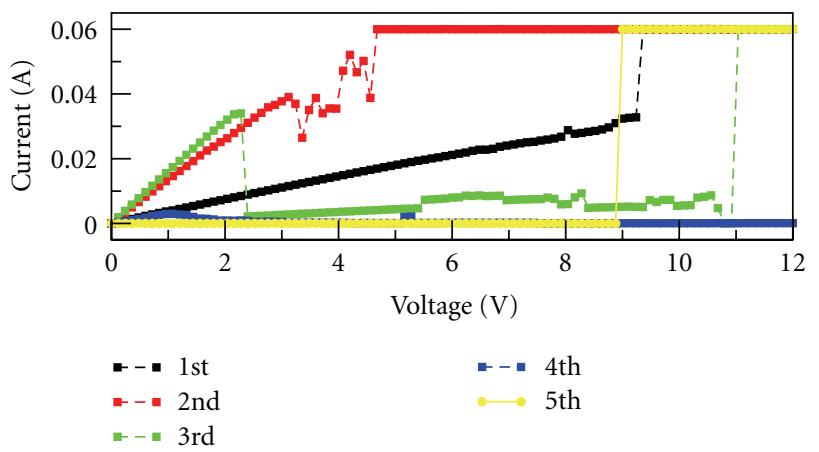

(d)

FIGURE 8: $I$ - $V$ behavior of a $17 \mathrm{~nm}$ PMMA device as a function of the compliance current. The electroforming of the device was realized using a compliance current of $20 \mathrm{~mA}$, and the bias voltage was swept from 0 to $8 \mathrm{~V}$. To study the effect of the compliance current on the formation and rupture of filaments, these were set at (a) $40 \mathrm{~mA}$, (b) $60 \mathrm{~mA}$, (c) $80 \mathrm{~mA}$, and (d) $60 \mathrm{~mA}$ (see text). The $I$ - $V$ measurements were sequentially performed on the MIM device.

than their formation and, therefore, the conductivity begins to decrease. In the fourth sweep, almost all the filaments were broken and the conductivity is minimal. The filamentary formation is initiated again in the following scan of the voltage. During sweeps performed in this voltage interval, it has been observed at first glance that the top electrode begins to degrade due to the intense electric fields and Joule heatings. All these results show that the compliance currents and voltage intervals are fundamental parameters for the formation and rupture of filaments in MIM devices.

\section{Conclusion}

We have obtained WORM memory devices by using the simple structure aluminum/insulator polymer/aluminum. In particular, we have used PMMA as well as PS like the insulator polymer, and the films have been deposited by spin coating technique using different solvents. The $I$ - $V$ behavior of the devices is independent of the solvent and polymer used, but this strongly depends on the thickness of the organic layer, the compliance current, and voltage intervals used during the voltages sweeps. The MIM devices show different behaviors as a function of the film thickness: (i) films having a thickness smaller than $10 \mathrm{~nm}$ are in short circuit, (ii) when the film thickness is between 11 and $20 \mathrm{~nm}$ the device shows a WORM behavior with two ON states, (iii) films with thicknesses between 20 and $25 \mathrm{~nm}$ present WORM memory with strong NDR, (iv) with thicknesses bigger than $25 \mathrm{~nm}$, polymer films show WORM memory, (v) finally, organic films bigger than $300 \mathrm{~nm}$ have insulator behavior. The negligible dependence of the insulator polymer type used for the memory devices leads us to conclude that the influence of the organic layer is minimal and we can attribute the memory effect to the metal electrodes. We consider that small metallic particles coming from the aluminum electrodes are introduced during the evaporation of the top electrode and/or from both electrodes during the voltage application. The introduction of these particles is the responsible mechanism of the conductivity switching in the devices and of the formation of metallic filaments. Thus, the existence of some devices with two ON state or with NDR region is obtained when some weak metallic filaments are irreversible broken due to the Joule heating.

\section{Acknowledgments}

The authors acknowledge Gladis Labrada, Francisco Ramírez Jacobo, and Dr. Miguel Avalos for technical assistance as well as LINAN at IPICYT for providing access to their characterization facilities. This paper was supported at UASLP 
by SEP-PROMEP through Grant no. 103.5/07/2574 and by CONACYT through Grant no. S-3148 and for scholarships (J. A. A.-Niño and A. O. Sustaita).

\section{References}

[1] J. C. Scott and L. D. Bozano, "Nonvolatile memory elements based on organic materials," Advanced Materials, vol. 19, no. 11, pp. 1452-1463, 2007.

[2] Q. D. Ling, D. J. Liaw, E. Y. H. Teo et al., "Polymer memories: bistable electrical switching and device performance," Polymer, vol. 48, no. 18, pp. 5182-5201, 2007.

[3] Y. Yang, J. Y. Ouyang, L. Ma, R. J. H. Tseng, and C. W. Chu, "Electrical switching and bistability in organic/polymeric thin films and memory devices," Advanced Functional Materials, vol. 16, no. 8, pp. 1001-1014, 2006.

[4] D. Tondelier, K. Lmimouni, D. Vuillaume, C. Fery, and G. Haas, "Metal/organic/metal bistable memory devices," Applied Physics Letters, vol. 85, no. 23, pp. 5763-5765, 2004.

[5] M. Cölle, M. Büchel, and D. M. de Leeuw, "Switching and filamentary conduction in non-volatile organic memories," Organic Electronics, vol. 7, no. 5, pp. 305-312, 2006.

[6] F. Verbakel, S. C. J. Meskers, R. A. J. Janssen et al., "Reproducible resistive switching in nonvolatile organic memories," Applied Physics Letters, vol. 91, no. 19, Article ID 192103, 2007.

[7] Y. S. Lai, C. H. Tu, D. L. Kwong, and J. S. Chen, "Bistable resistance switching of poly(N-vinylcarbazole) films for nonvolatile memory applications," Applied Physics Letters, vol. 87, no. 12, Article ID 122101, pp. 1-3, 2005.

[8] H. S. Majumdar, A. Bolognesi, and A. J. Pal, "Memory applications of a thiophene-based conjugated polymer: capacitance measurements," Journal of Physics D, vol. 36, no. 2, pp. 211215, 2003.

[9] M. Beinhoff, L. D. Bozano, J. C. Scott, and K. R. Carter, "Design and synthesis of new polymeric materials for organic nonvolatile electrical bistable storage devices: poly(biphenylmethylene)s," Macromolecules, vol. 38, no. 10, pp. 4147-4156, 2005.

[10] M. Lauters, B. McCarthy, D. Sarid, and G. E. Jabbour, "Multilevel conductance switching in polymer films," Applied Physics Letters, vol. 89, no. 1, Article ID 013507, 2006.

[11] A. R. Elsharkawi and K. C. Kao, "Switching and memory phenomena in anthracene thin films," Journal of Physics and Chemistry of Solids, vol. 38, no. 1, pp. 95-96, 1977.

[12] C. H. Tu, Y. S. Lai, and D. L. Kwong, "Memory effect in the current-voltage characteristic of 8-hydroquinoline aluminum salt films," IEEE Electron Device Letters, vol. 27, no. 5, pp. 354-356, 2006.

[13] M. Terai, K. Fujita, and T. Tsutsui, "Electrical bistability of organic thin-film device using Ag electrode," Japanese Journal of Applied Physics, vol. 45, no. 4, pp. 3754-3757, 2006.

[14] S. Baek, D. Lee, J. Kim, S. H. Hong, O. Kim, and M. Ree, "Novel digital nonvolatile memory devices based on semiconducting polymer thin films," Advanced Functional Materials, vol. 17, no. 15, pp. 2637-2644, 2007.

[15] L. P. Ma, J. Liu, and Y. Yang, "Organic electrical bistable devices and rewritable memory cells," Applied Physics Letters, vol. 80, no. 16, pp. 2997-2999, 2002.

[16] T. Ouisse and O. Stéphan, "Electrical bistability of polyfluorene devices," Organic Electronics, vol. 5, no. 5, pp. 251-256, 2004.
[17] L. D. Bozano, B. W. Kean, V. R. Deline, J. R. Salem, and J. C. Scott, "Mechanism for bistability in organic memory elements," Applied Physics Letters, vol. 84, no. 4, pp. 607-609, 2004.

[18] J. Y. Ouyang, C. W. Chu, C. R. Szmanda, L. Ma, and Y. Yang, "Programmable polymer thin film and non-volatile memory device," Nature Materials, vol. 3, no. 12, pp. 918-922, 2004.

[19] C. W. Chu, J. Y. Ouyang, J. H. Tseng, and Y. Yang, "Organic donor-acceptor system exhibiting electrical bistability for use in memory devices," Advanced Materials, vol. 17, no. 11, pp. 1440-1443, 2005.

[20] J. K. Baral, H. S. Majumdar, A. Laiho et al., "Organic memory using [6,6]-phenyl-C61 butyric acid methyl ester: morphology, thickness and concentration dependence studies," Nanotechnology, vol. 19, no. 3, Article ID 035203, 2008.

[21] H. S. Majumdar, J. K. Baral, R. Österbacka, O. Ikkala, and H. Stubb, "Fullerene-based bistable devices and associated negative differential resistance effect," Organic Electronics, vol. 6, no. 4, pp. 188-192, 2005.

[22] J. A. Ávila-Niño, E. Segura-Cárdenas, A. O. Sustaita, I. CruzCruz, R. López-Sandoval, and M. Reyes-Reyes, "Nonvolatile write-once-read-many-times memory device with functionalized-nanoshells/PEDOT:PSS nanocomposites," Materials Science and Engineering B, vol. 176, no. 5, pp. 462-466, 2011.

[23] G. Simmons and R. R. Verderber, "New conduction and reversible memory phenomena in thin insulating films," Proceedings The Royal Society A, vol. 301, no. 1464, pp. 77-102, 1967.

[24] R. E. Thurstans and D. P. Oxley, "The electroformed metalinsulator-metal structure: a comprehensive model," Journal of Physics D, vol. 35, no. 8, pp. 802-809, 2002.

[25] H. Carchano, R. Lacoste, and Y. Segui, "Bistable electrical switching in polymer thin films," Applied Physics Letters, vol. 19, no. 10, pp. 414-415, 1971.

[26] Y. Segui, B. Ai, and H. Carchano, "Switching in polystyrene films: transition from on to off state," Journal of Applied Physics, vol. 47, no. 1, pp. 140-143, 1976.

[27] L. F. Pender and R. J. Fleming, "Memory switching in glow discharge polymerized thin films," Journal of Applied Physics, vol. 46, no. 8, pp. 3426-3431, 1975.

[28] W. J. Joo, T. L. Choi, J. Lee et al., "Metal filament growth in electrically conductive polymers for nonvolatile memory application," Journal of Physical Chemistry B, vol. 110, no. 47, pp. 23812-23816, 2006.

[29] G. Dearnaley, A. M. Stoneham, and D. V. Morgan, "Electrical phenomena in amorphous oxide films," Reports on Progress in Physics, vol. 33, no. 3, pp. 1129-1191, 1970.

[30] S. Pyo, L. Ma, J. He, Q. Xu, Y. Yang, and Y. Gao, "Experimental study on thickness-related electrical characteristics in organic/metal-nanocluster/organic systems," Journal of Applied Physics, vol. 98, no. 5, Article ID 054303, 6 pages, 2005.

[31] D. C. Prime, Switching mechanisms, electrical characterization and fabrication of nanoparticle based non-volatile polymer polymer memory devices, Ph.D. thesis, De Montfort University, Leicester, UK, 2010.

[32] W. L. Kwan, B. Lei, Y. Shao, S. V. Prikhodko, N. Bodzin, and Y. Yang, "Direct observation of localized conduction pathways in photocross-linkable polymer memory," Journal of Applied Physics, vol. 105, no. 12, Article ID 124516, 2009. 

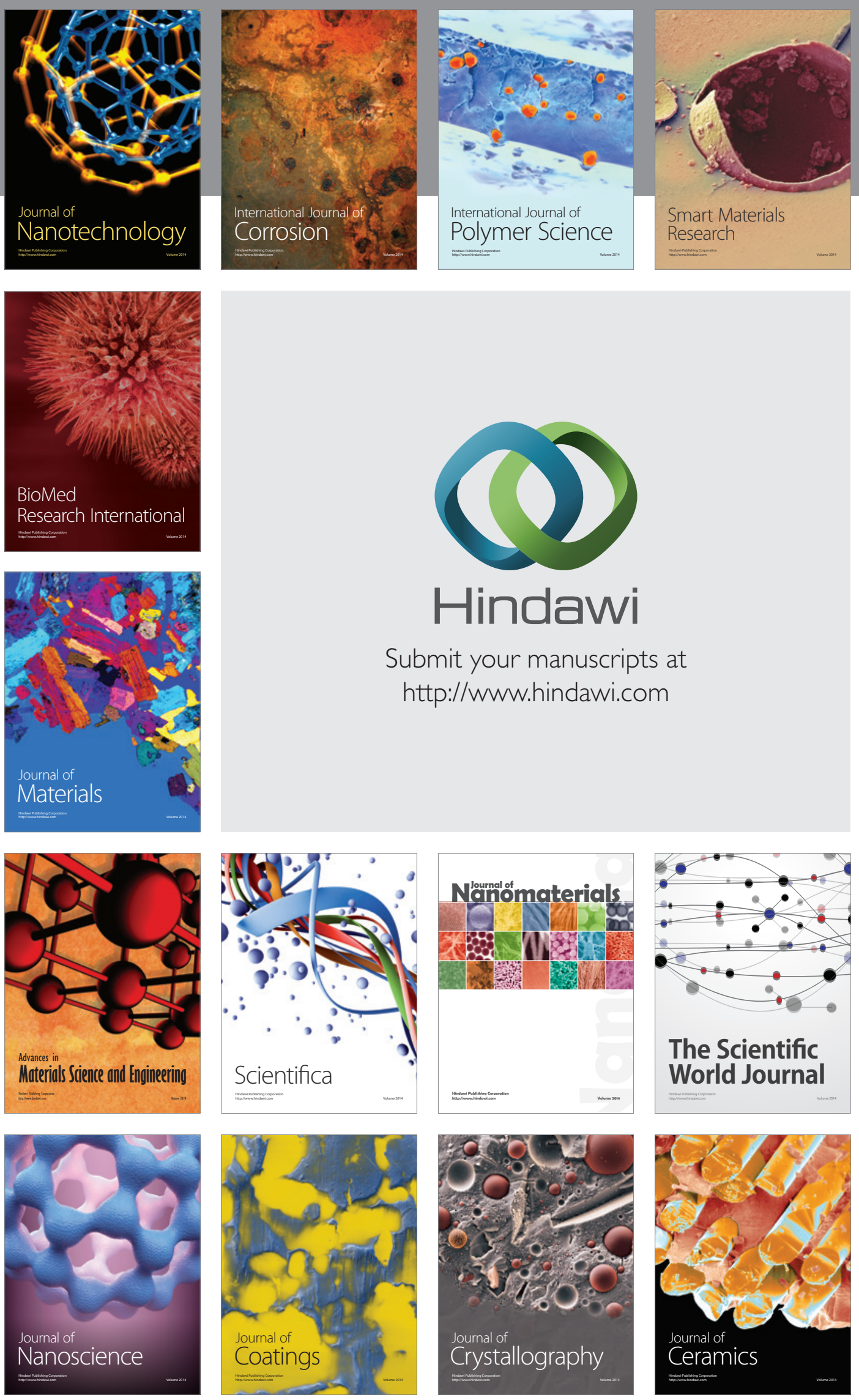

The Scientific World Journal

Submit your manuscripts at

http://www.hindawi.com

\section{World Journal}

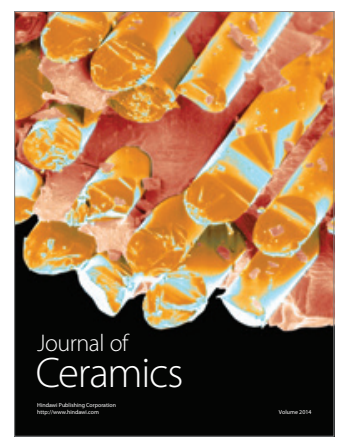

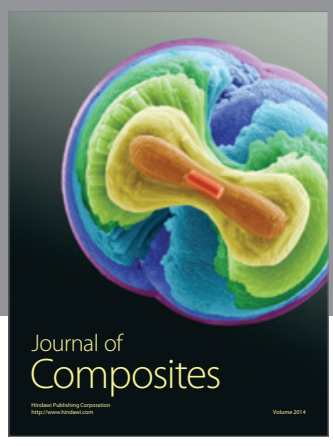
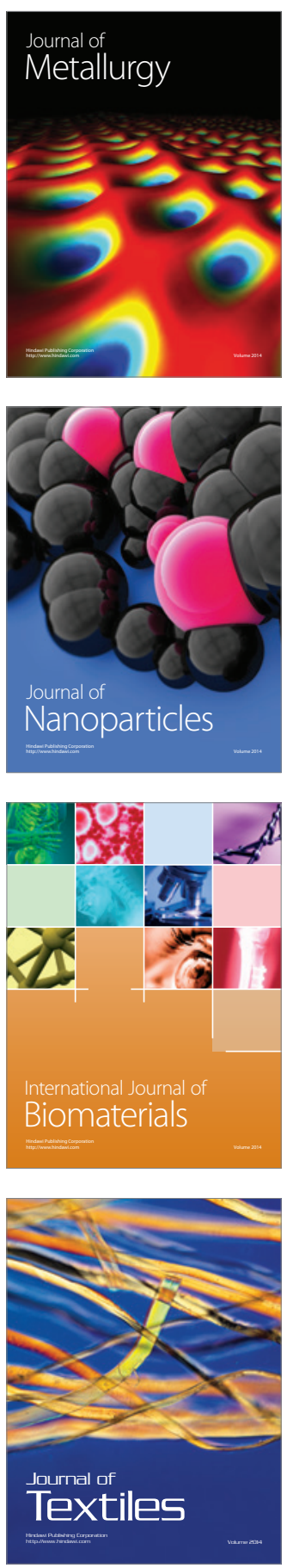